\title{
EFFECTIVE ORGANIZATION OF THE EDUCATIONAL PROCESS AS ONE OF THE MOST TOPICAL ISSUES IN THE MODERN TEACHING METHODS OF FOREIGN LANGUAGES
}

\author{
An Y.D., Zhdanova E.A., Alken S.H., Rakhmetova G.Sh. \\ Karaganda Technical University, Karaganda, email: yekaterina.an@gmail.com \\ The long standing practice of educational work shows the importance of not sidestepping educational issues in \\ the organization of educational activities, as well as the use of effective methods of teaching foreign languages, both \\ traditional and intensive. The rational organization of the content of the educational process is based on the technology \\ of teaching spoken language in a foreign language directly on the material of informative texts for reading and applying \\ active methodical and psychological learning techniques, which create a favourable environment for the management \\ of educational activities: allow for close interaction with students, which contributes to the achievement of accelerated \\ development of communication skills in a foreign language, developing skills in prepared and unprepared monologue \\ and dialogue speech, as well as at the level of polylogue. Foremost teaching of reading, a priority in relation to speak- \\ ing, the use of thematically related informative texts and an analytical-synthetic method of work on them, as well as a \\ certain system of presentation of study material (sequence of actions, their goals), its strengthening (training), provid- \\ ing multiple encounters with the text, imprinting it in memory, keeping it in it, and the use of the textual material in \\ communication practice, allow to ensure the interconnected nature of teaching the main types of speech activity and, \\ most importantly, provide an opportunity for the accelerated developing speaking skills.
}

Keywords: intensive, strengthening, skimming, introducing, practice in communication

The achievements of recent years in the development of modern technologies and, at the same time, the development of intellectual programs for independent study of languages, of course, cannot fully replace the teacher, who is the central figure of any educational process. The success of training and, ultimately, the solution of the problems facing the education system and society largely depends on his/her qualifications and professionalism.

As is known, the new requirements of society for education and personal development, new living conditions are changing both teaching methods and the content of pedagogical practice. $[1,2]$. In this regard, the development of innovative teaching methods that correspond to the current goals of education, aimed at intensifying and optimizing the educational process as the most important principles of the scientific organization of labor, is not only a pedagogical, but also a social task [3].

The currently increased need for teachers to clarify many specific provisions of existing methodological systems, in particular, intensive methods of teaching foreign languages, dictated the need to describe certain aspects of the theory and practice of communicative teaching of foreign languages, which cause difficulties in understanding and interpretation, especially among teachers, beginners in teaching at the university.

Unfortunately, the problem of organizing the content of spoken language on the basis of reading texts has not yet been sufficiently solved and adequate attention is not paid to such a type of speech activity as an analytical-synthetic work, which involves the implementation of a communicative inten- tion due to mastering linguistic material, skills and abilities to operate it. Learning to read is mainly designed to extract information, which is achieved through the development of differentiated reading skills (by scanning, skimming and reading comprehension). It is known that with the development of the ability to read with the direct extraction of information, the transition to independent reading is carried out: informative reading by its nature is close to authentic reading [4].

However, no less important is the function of reading as an effective tool for developing speaking skills.

Research Objective: Based on the specific conditions of communicative teaching of a foreign language in a non-linguistic university, the main goal is to develop and implement an effective technology of teaching a foreign language, which allows to optimize the educational process, namely: to strengthen the motivation of learning and to ensure the acceleration of the pace of educational actions, to intensify learning activities.

\section{Materials and methods of research}

The current stage of the methodology of teaching foreign languages is characterized by a communicative orientation, when it is not the memorization of vocabulary and grammatical rules that becomes decisive in the learning process, but the implementation by students of their own communicative intentions. Communication-oriented learning, accordingly, should be determined by the appropriate content of the learning process, as well as by a certain system of interaction between the teacher and students [5]. 
Thus, efficiency in the organization of the educational process can be achieved through its intensification by strengthening the motivation of learning, by maximizing the joint efforts of the teacher and students involved in the educational process, thanks to the activation of their psychological potential, the product of which is the formation of foreign language skills $[6,7]$.

Certainly, intensification aimed at improving the educational process of teaching a foreign language can be achieved methodically based on a special organization of educational material, its concentration and clear distribution, as well as through specific forms and active teaching methods.

Inappropriate selection and organization (volume, distribution, structure) of educational material significantly hinder the implementation of the set goals. Therefore, for the successful management of educational activities, the teacher needs to decide, firstly, on the basis of what material he plans to implement the set goals and, secondly, with the help of what means he can intensify the process of mastering the communicative function of the target language.

\section{Results of the study and their discussion}

The work practices according to the intensive methodology shows the relevance of the parallel development of all types of speech activity, based on their integration and interrelation both in one lesson and in the system of lessons.

It is also important to take into account the corresponding hierarchical subordination of learning goals and types of speech activity. At the same time, the primary role here is given to reading. The formation and development of communicative competence can be accelerated to a large extent due to such a reading function as serving as an effective means for developing speaking skills.

The teaching comprehension ahead of speaking provides a real opportunity to accelerate the formation of speaking skills. The selection and rational organization of educational material according to a thematic principle in the system of classes - system of interrelated classes, representing a holistic unity in terms of structure and content to a greater extent - contribute to the optimization of the educational process. However, it is important to remember that each lesson in the system of thematically united lessons has its own characteristics and specificity: purpose, content, structure and logic of construction.
When planning and methodological development of training sessions on a specific topic, it is also important to rationally distribute the material intended for active assimilation (common to all types of speech activity) and the material that will be assimilated passively [8]. It should be considered that the "spoken" text (text-dialogue) that is used to develop the skills of prepared speech is fundamentally different in character from the texts used in reading teaching, written speech with all its features (syntax complexity, etc.). In this connection, the Speech Learning Technology proposed by the author of this work is based on two techniques, namely, the intensive method of strengthening the psychological reserves of the individual and the team [9] as well as

the analytical-synthetic method of scientific word processing based on scanning, skimming, reading comprehension of informative texts and following them abstracting, annotating, structural and semantic transformation of sentences etc. .in order to prepare practical material for monologues and dialogues. The proposed technology makes it possible to increase the pace of training by means of an agreed joint activity and a specific system for supplying training material (introducing), fixing it through a repeated meeting with the text in memory and retaining it therein (activization and training) and the practical application of the material in communication.

Thematically grouped texts provide a structured framework for developing the skills of both prepared and untrained students. These texts are being incorporated into the training process to deal with them in the context of the proposed situations.

Acquaintance, activation and application of the learned text material are assisted by a system of techniques that should be aimed at solving specific problems. For example, the formation of the skills of text compression, the extraction of basic ideas, the skills of semantic transformation and the structural design of statements based on the material of the text, etc. ensure the effectiveness of the educational process, is fertile ground for the formation of skills not only in speaking, but also in all types of speech activity. However, it should be emphasized that the effectiveness of training depends not only on what forms and methodological methods of working on textual material are used, but also on whether or not the nature of the texts and the structural and compositional characteristics of texts-description, texts-message, texts-reasoning are taken into account etc. 
The strong assimilation of thematic vocabulary can be facilitated not only by special exercises for recognition, linguistic guessing and other tasks when presenting lexical material both in general and in isolation, but also by the nature of the presentation or introduction of the text. When introducing a teaching text, particular mention should be made of the role of the mother tongue, which is useful only to the extent that it is necessary to understand what has been said. It helps students navigate the content of what they hear and helps the teacher monitor understanding. If the teaching material is a high-level or voluminous text, it should be divided into parts or pieces of meaning and introduced separately. A clear dismemberment and coherence of material are essential for effective memory. A work on a single piece of text can be done, including a series of pre- and speech exercises prior to students performing communicative tasks at the training and speech practice stage. When teaching material is introduced it should be especially noted the role of the native language, which is advisable to use only to the extent that it is necessary for comprehending what was heard. It helps students to correctly navigate the content of what they have heard, and the teacher to control understanding. At this stage, it is advisable for the teacher to present the text repeatedly: without relying on the text, phrase by phrase, to acquaint the learners with the contents of the new text with an understanding of its main contents, and translate, if necessary, individual words and sentences in the mother tongue.

Multiple presentation of the text based on the choral pronunciation of the text material by the students following the teacher without relying on the text allows the connection of articulatory-motor memory, which ensures better memorization of the material. After all, assimilation is achieved, as is known, with the help of imitation. Also, reading the text aloud: reading the text independently or in groups helps to memorize it better.

Efficiency and method of synchronous translation of text from a foreign language into a native language and vice versa should be noted, which also significantly stimulates the active thinking activity of the student. At the same time, in order to help students to remember and focus on language material, emphasis should be placed on the intonation that has been tested in the practice of psychotherapy.

The next step after the introduction of the text is the intensification of the text in order to develop the skills of prepared monologue as well as dialogue speech within the studied text. It is good practice to retell the text with a verbatim transmission of its content or close to it during the assimilation of the text [10].

Preparatory work for retelling the text may include working out the phonetic side (sounds, intonation, melodic speech, syntagmatic division of sentences, rhythm and etc. The text is subject to a number of transformations: the length of the retelling may be less than the original text; complex grammatical constructions are replaced, as well as purely textual words typical of writing, by simpler spoken language. It is possible to use colloquial constructions included in the source text; to replace direct speech with indirect speech and etc.

Work to prepare material for the recitation of a large text may include elements of abstracting. It should be borne in mind that abstraction is not only a reduction in the length of the original text, combined with the conversion of direct speech into indirect speech. The abstract may also include a statement of one's own attitude to the events described in the text.

It is very important to note that a retelling of a text as a way of developing monological speech should not be seen only as an outcome in the development of this form of speech. Monologues could and should be included, motivated and therefore communicatively colored [11].

At the stage of training in communication it is necessary to formulate such communicative tasks, which can stimulate, "compel" students to use certain linguistic and speech models of activated educational material. In short, it is very important to formulate a study assignment in a such way as to provide an incentive for speech action [12].

The practice of communicating promotes the development of untrained speech, and encourages the independent choice and use of language and speech by students. It may be proposed to find a problem situation (the theme of the game), move from reporting to discussing material, that is not just to ask a question and answer the material studied, but to find issues of interest for discussion, exchange of views within the known knowledge [13].

\section{Conclusions}

Practice shows that organized student cooperation in the stages of communication, training and practice in various forms of interaction (in pairs, threes, groups, teams) creates favorable conditions for the formation of communication skills (monological, dialogue and polylogical speech) through the development 
of interpersonal relations. The chosen form of organization of the educational process based on a combination of traditional and intensive methods of teaching foreign language speaking on the basis of the principles of the correlation of teaching and educational systems, has increased the effectiveness of teaching activities. The knowledge levels and language skills have been improved in almost all areas of speech and so the speed of responses to questions, the number of individual statements and the use of complex phrases have been increased; the depth and subject area of students' questions have been changed.

Furthermore not only the students develop the skills to communicate, but also they are able to keep up the conversation doing, lead the communication and direct it to a certain subject (so-called "idea generators").

Some of the significant practical benefits of this technology include: the opportunity to organize students into a group in a short time; to help them to adapt easily to the learning environment and teaching style; to help students to perform tasks that are seemingly impossible in terms of content and subject area from the first point of view; to be able to complete tasks from prepared to untrained speech successfully, and to enjoy and be satisfied with their own achievements. Certainly it encourages learners to achieve success, to get new knowledge and skills in learning a foreign language $[14,15]$.

Intensive method is a field of extensive activity, because it is a flexible system that allows to vary the content of the subject and the educational process according to different conditions and requirements for communicative learning.

The experience has shown that the development of the communication skills has been improved due to the method of strengthening the psychological potential of the individual and the team, the active methods of teaching speaking and the use of scientifically processed text materials. The proposed foreign language teaching intensive technology allows to accelerate the process of achieving the practical results.

\section{References}

1. Lomakina E.A. Personality-oriented approach in teaching a foreign language // Modern methods and technologies of teaching foreign languages: collection of works. Magnitogorsk State Technical University. G.I. Nosova, 2019. P. 46-50. (in Russian).

2. Volkova E.G. On the question of linguistic aspects of intercultural communication // Man and culture. 2015. No. 1. P. 42-71. (in Russian).

3. Belyakova E.M., Prokopyev A.V. Innovative teaching methods in education // Modern problems of science and education. 2015. No. 2 (part 1). 2015. URL: http://science-education. $\mathrm{ru} / \mathrm{ru} / \mathrm{article} / \mathrm{view}$ ?id=18898 (in Russian).

4. Serova T.S. Characteristics and functions of professionally oriented reading in educational and research activities of students, graduate students and university teachers // Bulletin of the Perm National Research Polytechnic University. Problems of linguistics and pedagogy. 2013. No. 7 (49). P. 3-12. (in Russian).

5. Zhilenko N.V. Personality-oriented technologies in teaching a foreign language // Lingua mobilis. 2011. No. 6 (32). P. 119-124. (in Russian).

6. Serostanova N.N. Intensification of the process of teaching a foreign language in a non-linguistic university through the use of interactive technologies. // Modern problems of science and education. 2015. No. 6. URL: http://science-education.ru/ru/ article/view?id=23597 (in Russian).

7. Rasulova M.Zh. Intensification of learning as a factor in improving the quality of education // Education throughout life: lifelong education for sustainable development. 2015. P. 299302. (in Russian).

8. Matukhin D.L. Professionally oriented teaching of a foreign language to students of non-linguistic specialties // Language and culture. Linguistics. 2011. No. 2. P. 121-129. (in Russian).

9. Kitaygorodskaya G.A. Methodology for intensive teaching of foreign languages. Moscow: Ed. Moscow University, 1986. 302 p. (in Russian).

10. Sokolova O.L., Skopova L.V. Organization of independent work on a foreign language at a university as a way of individualization of training // Nizhniy Novgorod education. 2016. No. 4. P. 65-72. (in Russian).

11. Sergeeva N.N. Foreign language communicative competence in the field of professional activity: model and methodology // Pedagogical education in Russia. 2014. No. 6. P. 147-150. (in Russian).

12. Erofeeva EV. French language Practical course on the development of oral speech skills: Uch. manual for stud. II course Ying-that in. lang. // Ural. state ped. un-t. Ekaterinburg, 2014. 211 p. (in Russian).

13. Shaimova G.A. Formation of communicative competence by means of the "role play" method // Young scientist. 2012. No. 8 (43). P. 382-383. URL: https://moluch.ru/archive/43/5168/ (date of access: 21.01.2021). (in Russian).

14. Yastrebova L.N. Principles of teaching a second foreign language as a specialty in a language university // Bulletin of the Tomsk State. ped. un-that. 2014. No. 8 (149). P. 75-79. (in Russian).

15. Flerov O.V. Features of teaching a second foreign language in a non-linguistic university // Modern education. 2015. No. 1. P. 1-25. (in Russian). 